\title{
(2) OPEN ACCESS \\ Exploring the implications of the new ICD-10-CM classification system for injury surveillance: analysis of dually coded data from two medical centres
}

\author{
Eduard A Poltavskiy (1) ,' Susan H Fenton, ${ }^{2}$ Oluseun Atolagbe, ${ }^{1}$ Banafsheh Sadeghi, ${ }^{3}$ \\ Heejung Bang, ${ }^{4}$ Patrick S Romano ${ }^{3}$
}

- Additional material is published online only. To view, please visit the journal online (http://dx.doi.org/10.1136/ injuryprev-2019-043519).

${ }^{1}$ Center for Healthcare Policy and Research, University of California Davis, Sacramento, California, USA

${ }^{2} S$ chool of Biomedical Informatics, University of Texas Health Science Center, Houston, Texas, USA

${ }^{3}$ Internal Medicine, University of California Davis School of Medicine, Sacramento, California, USA

${ }^{4}$ Public Health Sciences, University of California Davis School of Medicine, Davis, California, USA

\section{Correspondence to} Dr Eduard A Poltavskiy, Center for Healthcare Policy and Research, University of California Davis, Sacramento, CA 95817, USA; eapoltavskiy@ ucdavis.edu

Received 6 May 2020

Revised 10 October 2020 Accepted 22 October 2020

\section{Check for updates}

(C) Author(s) (or their employer(s)) 2021. Re-use permitted under CC BY-NC. No commercial re-use. See rights and permissions. Published by BMJ.

To cite: Poltavskiy EA, Fenton SH, Atolagbe 0 , et al. Inj Prev 2021;27:i19-i26.

\begin{abstract}
Introduction External cause of injury matrices is used to classify mechanisms/causes of injuries for surveillance and research. Little is known about the performance of the Centers for Disease Control and Prevention's new external cause of injury matrix for Clinical Modification of the 10th Revision of the International Classification of Diseases (ICD-10-CM), compared with the ICD-9-CM version.

Methods Dually coded (ICD-9-CM and ICD-10-CM) administrative data were obtained from two major academic trauma centres. Injury-related cases were identified and categorised by mechanism/cause and manner/intent. Comparability ratios (CR) were used to estimate the net impact of changing from ICD-9CM to ICD-10-CM on the number of cases classified to each mechanism/cause category. Chamberlain's percent positive agreements (PPA) were calculated and McNemar's test was used to assess the significance of observed classification differences.
\end{abstract}

Results Of 4832 and 5211 dual-coded records from the two centres, 632 and 520 with injury-related principal diagnoses and external cause codes in both ICD-9-CM and ICD-10-CM were identified. CRs for the mechanisms/ causes with at least 20 records ranged from 0.85 to 1.9 at one centre and from 0.97 to 1.07 at the other. Among these mechanisms/causes, PPAs ranged from 33\% for 'other transport' to $94 \%$ for poisoning at one centre, and from $75 \%$ for 'other transport' to $100 \%$ for fires/burns at the other centre. Case assignment differed significantly for falls, motor vehicle traffic, other transport, and 'struck by/against' injuries at one centre, and for 'other pedal cyclist' at the other centre.

Conclusion Switching to ICD-10-CM and the new external cause of injury matrix may affect injury surveillance and research, especially for certain mechanisms/causes.

\section{INTRODUCTION}

From 1979 through September 2015, the Clinical Modification of the 9th Revision of the International Classification of Diseases (ICD-9-CM) was used in the USA to code morbidity data. ${ }^{1}$ On 1 October 2015, the Clinical Modification of the 10th Revision of ICD (ICD-10-CM), ${ }^{2}$ developed by the National Center for Health Statistics (NCHS) and the Centers for Medicare \& Medicaid Services, was implemented in the USA for classification and coding of morbidity data. ICD-10-CM codes provide much more detail about diseases, injuries, and external causes of injuries than ICD-9-CM codes, making this classification system more useful for measuring quality of care, public health surveillance and epidemiological research. ${ }^{3}$

The International Classification of Diseases $(\mathrm{ICD})^{4}$ injury matrices are nationally and internationally recognised tools or frameworks for organising and reporting ICD-coded injury data. These tools have multiple versions based on different clinical modifications of the ICD, and can categorise both external cause codes, which describe the mechanism and intent of injury, and diagnosis codes, which describe the body region and type of injury. ${ }^{5}$ The ICD-9-CM external cause of injury matrix (hereafter referred to as matrix) was used extensively to generate county, state, regional, national and international comparisons of non-fatal injury data. The ICD-10-CM matrix should prove to be similarly useful over the next decade.

Data from Sweden suggest that the conversion to ICD-10 may have been associated with important discontinuities in observed rates at the mechanism/cause level. ${ }^{6}$ To interpret injury morbidity data across the transition from ICD-9-CM to ICD-10-CM in the USA, it would be helpful to understand any differences in how the same records would be classified using the ICD-9-CM and ICD-10-CM matrices. We were able to obtain such dually coded data from two large academic trauma centres and apply both matrices to estimate comparability ratios (CRs) and identify potential reasons for discrepant classification of mechanism/cause.

\section{METHODS \\ Dually coded data}

Hospital inpatient discharge data independently coded according to ICD-9-CM and ICD-10-CM Official Guidelines for Coding and Reporting in two university medical centres located in California (MCA) and in the Midwest (MCB) were used for this study. These data were generated in the ordinary course of business, as part of the process of training and supervising professional coders and predicting the local financial impact of the code set conversion.

At MCA, dual coding was usually done by the same coder, during the same reading of the original record, although in some cases, ICD-10-CM coding was performed by a different coder after the ICD-9-CM coded claim had been submitted. All professional coders at MCA had sufficient 
experience with ICD-10-CM to be classified as proficient in ICD-10-CM coding. A deidentified version of this dually coded dataset with 5167 systematically sampled records from September 2014 through September 2015 was obtained. From this dataset, 335 records that were originally coded as inpatient claims but later reconciled as 'observation stay' or ambulatory claims were excluded, leaving 4832 records for analysis.

At $\mathrm{MCB}$, dual coding was typically done by different coders after the ICD-9-CM coded claim had been submitted. The prior ICD-9-CM coding was not available to the coders performing ICD-10-CM coding. All professional coders were internally trained in ICD-10-CM and had sufficient experience to be classified as proficient in ICD-10-CM. A deidentified version of this dually coded dataset with 5305 systematically sampled records from 2011 and 2012 was obtained. From this dataset, 94 records were excluded because of the absence of valid diagnosis codes, leaving 5211 inpatient records for analysis.

The University of California Davis Institutional Review Board (ID =986385) determined that this study did not involve human subjects at either site. Due to unavoidable differences in dual coding methods and time periods, we chose to analyse MCA and MCB data separately.

\section{Tabulation of injury-related hospitalisation data}

To describe the dually coded datasets, the numbers of diagnosis (DX) codes, external cause of injury and poisoning codes, and unique codes were summarised at each step of the data preparation and selection process.

The latest version of the SAS Input Statements for ICD-9-CM External Cause of Injury Morbidity Matrix was downloaded from http://www.cdc.gov/nchs/injury/injury_tools.htm and used for analysis of ICD-9-CM data. The latest ICD-9-CM nature-ofinjury codes, ${ }^{7}$ ICD-10-CM surveillance case definition for injury hospitalisations, ${ }^{8}$ and SAS program for the ICD-10-CM External
Cause of Injury Matrix were obtained from the NCHS. The following analysis was carried out in two steps: (1) identifying injury cases based on the presence of specific injury diagnosis codes (table 1) in the principal diagnosis field, and (2) searching for valid external cause of injury codes in the following order: all labelled external cause fields, the principal diagnosis field and diagnosis fields other than principal diagnosis, to identify the first listed valid external cause of injury code and to create a table showing injury mechanism/cause by injury intent.

\section{Effect of change and agreement measures}

The injury mechanism-by-intent tables were generated and differences in case assignment were investigated. We estimated $\mathrm{CR}, C R_{i}=\frac{D_{i, I C D-10-C M}}{D_{i, I C D-9}-C M}$ where $D_{i, \text { ICD-10-CM }}$ is the number of injuries due to cause/mechanism $i$ classified by ICD-10-CM and $D_{i \text { ICD-9.CM }}$ is the number of injuries due to cause/mechanism $i$ classified by ICD-9-CM, to describe the effect of implementing ICD-10-CM on the count of cases in the mechanism-by-intent cells of the matrix. ${ }^{9}$ The CRs based on small cell numbers (less than 20) were considered as unreliable because of potential sample bias. ${ }^{9}$

McNemar's test with continuity correction on paired proportions was used to assess the significance of changes in the same mechanisms/causes of the ICD-9-CM and ICD-10-CM matrices. The significance level (alpha) was equal to 0.05 .

To evaluate the agreement between ICD-9-CM and ICD-10-CM versions of the matrix applied to the dually coded data, Chamberlain's percent positive agreements $(\mathrm{PPA})^{10}$ were calculated. PPA is the number of cases classified as the same mechanism/cause by both ICD-9-CM and ICD-10-CM matrices divided by the number of cases classified as that mechanism/ cause by at least one matrix. PPA was selected because it is more

Table 1 Criteria for identifying valid injury cases based on the principal diagnosis field

\section{ICD-9-CM}

\begin{tabular}{|c|c|}
\hline Nature of injury code & Types of injuries \\
\hline $\begin{array}{l}800-909.2 \\
909.4 \\
909.9\end{array}$ & $\begin{array}{l}\text { Fractures; dislocations; sprains and strains; intracranial injury; internal injury of thorax, abdomen, and pelvis; open wound of } \\
\text { the head, neck, trunk, upper limb and lower limb; injury to blood vessels; late effects of injury, poisoning, toxic effects, and } \\
\text { other external causes, excluding late effects of complications of surgical and medical care or drugs, medicinal or biological } \\
\text { substances. }\end{array}$ \\
\hline $910-994.9$ & $\begin{array}{l}\text { Superficial injury; contusion; crushing injury; effects of foreign body entering through orifice; burns; injury to nerves } \\
\text { and spinal cord; traumatic complications and unspecified injuries; poisoning and toxic effects of substances; other and } \\
\text { unspecified effects of external causes. }\end{array}$ \\
\hline $995.5-995.59$ & Child maltreatment syndrome. \\
\hline $995.80-995.85$ & $\begin{array}{l}\text { Adult maltreatment, unspecified; adult physical abuse; adult emotional/psychological abuse; adult sexual abuse; adult } \\
\text { neglect (nutritional); other adult abuse and neglect. }\end{array}$ \\
\hline \multicolumn{2}{|r|}{ ICD-10-CM } \\
\hline $\begin{array}{l}\text { Nature of injury code } \\
\text { (any seventh character except } D-R \text { ) }\end{array}$ & Types of injuries \\
\hline All S codes & Anatomic injuries. \\
\hline T07-T34 & Foreign bodies, burns, corrosions, frostbite. \\
\hline $\begin{array}{l}\text { T36-T50 with a sixth character of } 1,2,3 \text {, or } 4 \text { (exceptions: T36.9, } \\
\text { T37.9, T39.9, T41.4, T42.7, T43.9, T45.9, T47.9, and T49.9 with a } \\
\text { fifth character of } 1,2,3, \text { or } 4 \text { ) }\end{array}$ & Drug poisoning (excludes adverse effects and underdosing). \\
\hline T51-T65 & Toxic effects of substances non-medicinal as to source. \\
\hline T66-T76 & $\begin{array}{l}\text { Other and unspecified effects of external causes (radiation, heat, light, hypo/hyperthermia, asphyxiation, child/adult abuse, } \\
\text { lightning, drowning, motion sickness). }\end{array}$ \\
\hline T79 & Certain early complications of trauma, not elsewhere classified. \\
\hline 09A2-09A5 & $\begin{array}{l}\text { Injury, poisoning, and certain other consequences of external causes; and physical, sexual and psychological abuse } \\
\text { complicating pregnancy, childbirth and the puerperium. }\end{array}$ \\
\hline T8404/M97 & Periprosthetic fracture around internal prosthetic joint. \\
\hline
\end{tabular}

ICD-9-CM, Clinical Modification of the 9th Revision of the International Classification of Diseases; ICD-10-CM, Clinical Modification of the 10th Revision of ICD (ICD-10-CM). 
Table 2 Sample selection and characteristics of the Clinical Modification of the 9th Revision of the International Classification of Diseases (ICD-9CM)/Clinical Modification of the 10th Revision of ICD (ICD-10-CM) dually coded datasets

\begin{tabular}{|c|c|c|c|c|c|}
\hline & \multirow[b]{2}{*}{ Characteristics } & \multicolumn{2}{|c|}{ MCA } & \multicolumn{2}{|c|}{ MCB } \\
\hline & & ICD-9-CM & ICD-10-CM & ICD-9-CM & ICD-10-CM \\
\hline Input & Number of unique records & \multicolumn{2}{|c|}{$N=5167$} & \multicolumn{2}{|c|}{$\mathrm{N}=5305$} \\
\hline \multirow[t]{7}{*}{ Step 1} & Number of inpatient records with at least one valid ICD-9-CM and ICD-10-CM diagnosis code & \multicolumn{2}{|c|}{$\mathrm{n}=4832$} & \multicolumn{2}{|c|}{$n=5211$} \\
\hline & Number of DX and external cause codes per record: $\min , \max$ & 1 to 48 & 1 to 62 & 1 to 91 & 1 to 94 \\
\hline & Number of external cause codes per record: $\min , \max$ & 0 to 6 & 0 to 5 & 0 to 8 & 0 to 5 \\
\hline & Number of unique DX and external cause codes & 3845 & 5310 & 4269 & 6150 \\
\hline & Mean number of DX and external cause codes per record & $\begin{array}{l}8.9 \\
(S D=6.5)\end{array}$ & $\begin{array}{l}8.4 \\
(S D=6.0)\end{array}$ & $\begin{array}{l}12.5 \\
(S D=8.1)\end{array}$ & $\begin{array}{l}12.3 \\
(S D=7.9)\end{array}$ \\
\hline & Number of unique external cause codes & 277 & 355 & 281 & 323 \\
\hline & Average number of external cause codes per record for records with at least one external cause code & $2.2(\mathrm{SD}=0.9)$ & $\begin{array}{l}2.2 \\
(S D=1.1)\end{array}$ & $\begin{array}{l}1.3 \\
(S D=0.6)\end{array}$ & $\begin{array}{l}1.3 \\
(\mathrm{SD}=0.8)\end{array}$ \\
\hline Step 2 & Number of records with a principal diagnosis of injury (see surveillance definitions, table 1) & $\mathrm{n}=657$ & $n=659$ & $n=537$ & $\mathrm{n}=544$ \\
\hline \multirow[t]{3}{*}{ Step 3} & Number of records with at least one valid external cause code from external cause of injury matrices & $n=657$ & $n=632$ & $\mathrm{n}=532$ & $n=526$ \\
\hline & Completeness of external cause coding* & $100 \%$ & $95 \%$ & $99 \%$ & $97 \%$ \\
\hline & Number of records that have at least one valid ICD-9-CM and one valid ICD-10-CM external cause code & \multicolumn{2}{|c|}{$\mathrm{n}=632$} & \multicolumn{2}{|c|}{$\mathrm{n}=520$} \\
\hline
\end{tabular}

*Number of records with at least one valid external cause of injury code/number of records where principal diagnosis is an injury code.

conservative than other measures of agreement when the prevalence of the condition is very low.

All statistical analyses except McNemar's test were performed in SAS V.9.4 (SAS Institute). R V.3.3.2 was used to perform McNemar's test.

\section{RESULTS}

\section{Case selection}

A total of 4832 records from MCA and 5211 records from MCB were included in the study and analysed in a parallel manner (table 2). On average, the ICD-9-CM subsets had more codes per record than the ICD-10-CM subsets: 8.9 versus 8.4 and 12.5 versus 12.3 in the MCA and MCB datasets, respectively. In the MCA dataset, 657 and 659 dually coded records had a principal diagnosis from the list of nature-of-injury codes shown in table 1, using ICD-9-CM and ICD-10-CM, respectively. In the MCB dataset, the corresponding numbers were 537 and 544 records, respectively.

In the MCA dataset, five records had an ICD-9-CM injury code as the principal diagnosis, but the ICD-10-CM principal diagnosis was not an injury code, whereas seven records had an ICD-10-CM injury code as the principal diagnosis, but the ICD-9-CM principal diagnosis was not an injury code (table 3). In the MCB dataset, one record had an ICD-9-CM injury code as the principal diagnosis, but the ICD-10-CM principal diagnosis was not an injury code, whereas eight records had an ICD-10-CM injury code as the principal diagnosis, but the ICD-9-CM principal diagnosis was not an injury code (table 3). Specifically, the ICD-10-CM case definition for injury has been slightly expanded by the NCHS, such that initial encounters for periprosthetic fractures around internal prosthetic joints (T84.04 before 10/01/2016; M97 thereafter) and encounters for injuries and abuse complicating pregnancy, childbirth and the puerperium (O9A.2-O9A.5) are now included. ${ }^{7}$ These expansions accounted for 9 of the additional 15 records that were selected as injuries based only on ICD-10-CM diagnoses, whereas the exclusion of subsequent encounters from the ICD-10-CM case definition accounted for five of the six records selected based only on ICD-9-CM diagnoses.

Among the selected injury records (table 2), the ICD-9-CM External Cause of Injury Morbidity Matrix SAS program identified 657 records in the MCA dataset and 532 records in the
MCB dataset with at least one valid external cause code. By comparison, the ICD-10-CM matrix SAS program identified 632 records in the MCA dataset and 526 records in the MCB dataset with at least one valid external cause code. Overall, the completeness of external cause of injury coding was significantly higher in ICD-9-CM subsets than in ICD-10-CM subsets: 100\% versus $95 \%$ at MCA and $99 \%$ versus $97 \%$ at $\mathrm{MCB}$, respectively (both $\mathrm{p}<0.01$ by Fisher's exact test).

For subsequent analyses, all records without valid external cause of injury codes in both ICD-9-CM and ICD-10-CM subsets were excluded, leaving 632 cases from the MCA dataset and 520 cases from the MCB dataset.

\section{External cause of injury matrices}

In the two analysed datasets (tables 4 and 5), 86\% and 90\% of cases were coded as unintentional injuries and fewer than $1 \%$ were coded as undetermined injuries; at least $50 \%$ of cases in both datasets were classified as either falls or motor vehicle traffic (MVT) related. The proportion of cases with assault in the final MCA dataset (9\%) was about twice that in the final MCB dataset (5\%).

For the mechanisms/causes with total ICD-9-CM and ICD-10-CM cell counts of at least 20 (tables 4 and 5), CRs for specific mechanisms/causes ranged from 0.85 for MVT to 1.9 for 'other transport' in the MCA dataset and from 0.97 for poisoning to 1.07 for 'other transport' in the MCB dataset. Among this same set of amply represented mechanisms/causes, PPAs ranged from $33 \%$ for 'other transport' to $94 \%$ for poisoning in the MCA dataset, and from $75 \%$ for 'other transport' to $100 \%$ for fires/burns in the MCB dataset.

In the MCA dataset, four mechanisms/causes had complete agreement on both the number of records classified $(C R=1)$ and the classification of the same records $(\mathrm{PPA}=100 \%)$ : drowning, firearm, natural/environmental, and suffocation. In the MCB dataset, two causes of injury had complete agreement on both the numbers of records classified and the classification of the same records: fire/burn and firearm. Several other mechanisms/ causes (fire/burn in the MCA dataset; natural/environmental, overexertion, 'struck by/against', 'not specified' in the MCB dataset) had $C R=1$ and PPA $<100 \%$, which indicates that the ICD-9-CM and ICD-10-CM versions of the matrix classified the 
Table 3 Injury case selection disagreements between the Clinical Modification of the 9th Revision of the International Classification of Diseases (ICD-9-CM) coded principal diagnosis and the Clinical Modification of the 10th Revision of the ICD (ICD-10-CM) coded principal diagnosis on the same dually coded records

\begin{tabular}{|c|c|c|c|c|c|}
\hline $\begin{array}{l}\text { Injury code: } \\
\text { Yes/No }\end{array}$ & $\begin{array}{l}\text { ICD-9-CM } \\
\text { principal DX }\end{array}$ & Description & $\begin{array}{l}\text { Injury code: } \\
\text { Yes/No }\end{array}$ & ICD-10-CM principal DX & Description \\
\hline \multicolumn{6}{|l|}{ MCA dataset } \\
\hline No & 648.93 & $\begin{array}{l}\text { Other current conditions classifiable } \\
\text { elsewhere of mother, antepartum condition or } \\
\text { complication }\end{array}$ & Yes & S39.91XA* & Unspecified injury of abdomen, initial encounter \\
\hline No & 996.44 & Periprosthetic fracture around prosthetic joint & Yes & T84.040A & $\begin{array}{l}\text { Periprosthetic fracture around internal prosthetic right } \\
\text { hip joint, initial encounter }\end{array}$ \\
\hline No & 648.93 & $\begin{array}{l}\text { Other current conditions classifiable } \\
\text { elsewhere of mother, antepartum condition or } \\
\text { complication }\end{array}$ & Yes & 09A.213 & $\begin{array}{l}\text { Injury, poisoning and certain other consequences } \\
\text { of external causes complicating pregnancy, third } \\
\text { trimester }\end{array}$ \\
\hline No & 996.44 & Periprosthetic fracture around prosthetic joint & Yes & $\mathrm{T} 84.042 \mathrm{~A}$ & $\begin{array}{l}\text { Periprosthetic fracture around internal prosthetic right } \\
\text { knee joint, initial encounter }\end{array}$ \\
\hline No & 996.44 & Periprosthetic fracture around prosthetic joint & Yes & $\mathrm{T} 84.042 \mathrm{~A}$ & $\begin{array}{l}\text { Periprosthetic fracture around internal prosthetic right } \\
\text { knee joint, initial encounter }\end{array}$ \\
\hline No & 996.44 & Periprosthetic fracture around prosthetic joint & Yes & T84.049A & $\begin{array}{l}\text { Periprosthetic fracture around unspecified internal } \\
\text { prosthetic joint, initial encounter }\end{array}$ \\
\hline No & 996.44 & Periprosthetic fracture around prosthetic joint & Yes & T84.043A & $\begin{array}{l}\text { Periprosthetic fracture around internal prosthetic left } \\
\text { knee joint, initial encounter }\end{array}$ \\
\hline Yes & 964.2 & Poisoning by anticoagulants & No & T45.512D & $\begin{array}{l}\text { Poisoning by anticoagulants, intentional self-harm, } \\
\text { subsequent encounter }\end{array}$ \\
\hline Yes & 824.4 & Bimalleolar fracture, closed & No & S82.841D & $\begin{array}{l}\text { Displaced bimalleolar fracture of right lower leg, } \\
\text { subsequent encounter for closed fracture with routine } \\
\text { healing }\end{array}$ \\
\hline Yes & 864.03 & $\begin{array}{l}\text { Injury to liver without mention of open wound } \\
\text { into cavity, laceration, moderate }\end{array}$ & No & S36.115D & Moderate laceration of liver, subsequent encounter \\
\hline Yes & 994.1 & Drowning and non-fatal submersion & No & T75.1XXD & $\begin{array}{l}\text { Unspecified effects of drowning and nonfatal } \\
\text { submersion, subsequent encounter }\end{array}$ \\
\hline Yes & 964.2 & Poisoning by anticoagulants & No & R79.1 & Abnormal coagulation profile \\
\hline \multicolumn{6}{|l|}{ MCB dataset } \\
\hline Yes & 927.3 & Crushing injury of finger(s) & No & S67.190D & $\begin{array}{l}\text { Crushing injury of right index finger, subsequent } \\
\text { encounter }\end{array}$ \\
\hline No & 736.39 & Other acquired deformities of hip & Yes & S72.21XA & $\begin{array}{l}\text { Displaced subtrochanteric fracture of right femur, } \\
\text { initial encounter for closed fracture }\end{array}$ \\
\hline No & 415.19 & Other pulmonary embolism and infarction & Yes & S20.211A & $\begin{array}{l}\text { Contusion of right front wall of thorax, initial } \\
\text { encounter }\end{array}$ \\
\hline No & 005.9 & Food poisoning, unspecified & Yes & T62.91XA & $\begin{array}{l}\text { Toxic effect of unspecified noxious substance eaten as } \\
\text { food, accidental (unintentional), initial encounter }\end{array}$ \\
\hline No & 333.0 & $\begin{array}{l}\text { Other degenerative diseases of the basal } \\
\text { ganglia }\end{array}$ & Yes & S93.402A & $\begin{array}{l}\text { Sprain of unspecified ligament of left ankle, initial } \\
\text { encounter }\end{array}$ \\
\hline No & V54.15 & $\begin{array}{l}\text { Aftercare for healing traumatic fracture of } \\
\text { upper leg }\end{array}$ & Yes & S72.391A & $\begin{array}{l}\text { Other fracture of shaft of right femur, initial encounter } \\
\text { for closed fracture }\end{array}$ \\
\hline No & 277.39 & Other amyloidosis & Yes & S06.340A & $\begin{array}{l}\text { Traumatic haemorrhage of right cerebrum without } \\
\text { loss of consciousness, initial encounter }\end{array}$ \\
\hline No & 996.44 & Periprosthetic fracture around prosthetic joint & Yes & $\mathrm{T} 84.040 \mathrm{~A}$ & $\begin{array}{l}\text { Periprosthetic fracture around internal prosthetic right } \\
\text { hip joint, initial encounter }\end{array}$ \\
\hline No & 996.44 & Periprosthetic fracture around prosthetic joint & Yes & $\mathrm{T} 84.041 \mathrm{~A}$ & $\begin{array}{l}\text { Periprosthetic fracture around internal prosthetic left } \\
\text { hip joint, initial encounter }\end{array}$ \\
\hline
\end{tabular}

*This record should have been assigned a principal diagnosis of 09A.2-, because 0 chapter codes for injury must be sequenced before S or T chapter codes according to ICD-10-CM Official Guidelines.

same number of records to those injury mechanisms/causes, but not exactly the same records.

Detailed analyses of discrepant mechanism/cause assignments are presented in online supplemental tables S1 and S2). In the MCA dataset, about $13 \%$ of MVT $(\mathrm{CR}=0.85)$ injuries based on the ICD-9-CM matrix were reassigned to the new category of 'motor vehicle (MV) nontraffic' in the ICD-10-CM matrix. Such reassignment affected two records (1.4\% of MVT) in the MCB dataset. About $65 \%$ and $67 \%$ of injuries classified by the ICD-9-CM matrix as other transport in the MCA and $\mathrm{MCB}$ datasets, respectively, were reassigned to the new category of 'other land transport' by the ICD-10-CM matrix. About $9 \%$ and $33 \%$ of injuries classified by the ICD-9-CM matrix as 'other pedal cyclist' in the MCA and MCB datasets, respectively, were reclassified as 'MVT pedal cyclist' by the ICD-10-CM matrix. About $8 \%$ and $2 \%$ of injuries classified by the ICD-9-CM matrix as falls in the MCA and MCB data sets, respectively, were reclassified as 'struck by/against', overexertion, machinery and 'other specified' causes by the ICD-10-CM matrix.

According to McNemar's test, there were significant differences between the ICD-9-CM matrix and the ICD-10-CM matrix on mechanism/cause assignment for falls $(p=0.014)$, MVT injuries $(p<0.001)$, other transport injuries $(p<0.001)$, and struck by/against injuries $(p=0.016)$ in the MCA dataset, but only for 'other pedal cyclist' injuries $(p=0.041)$ in the MCB dataset. 


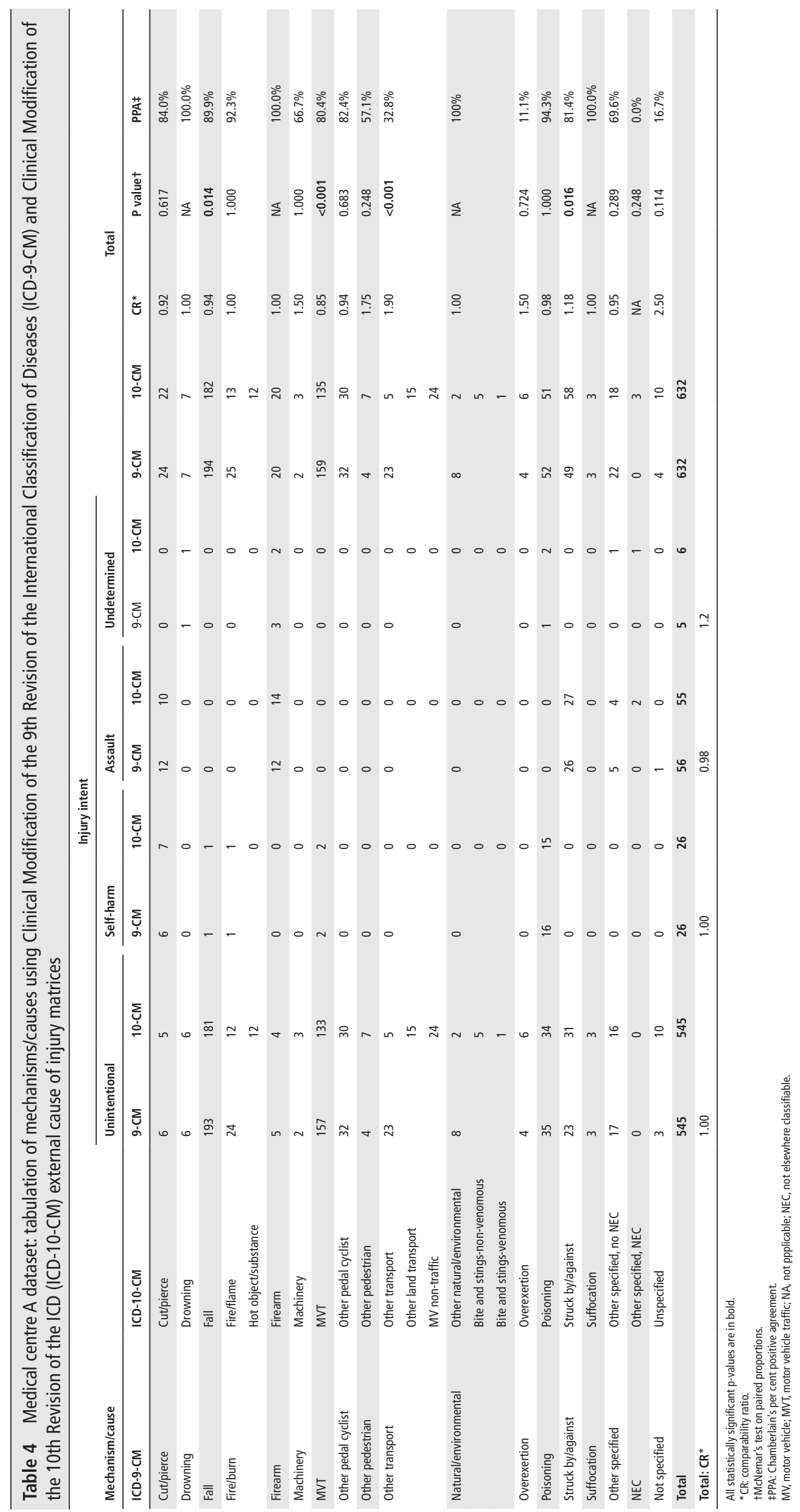




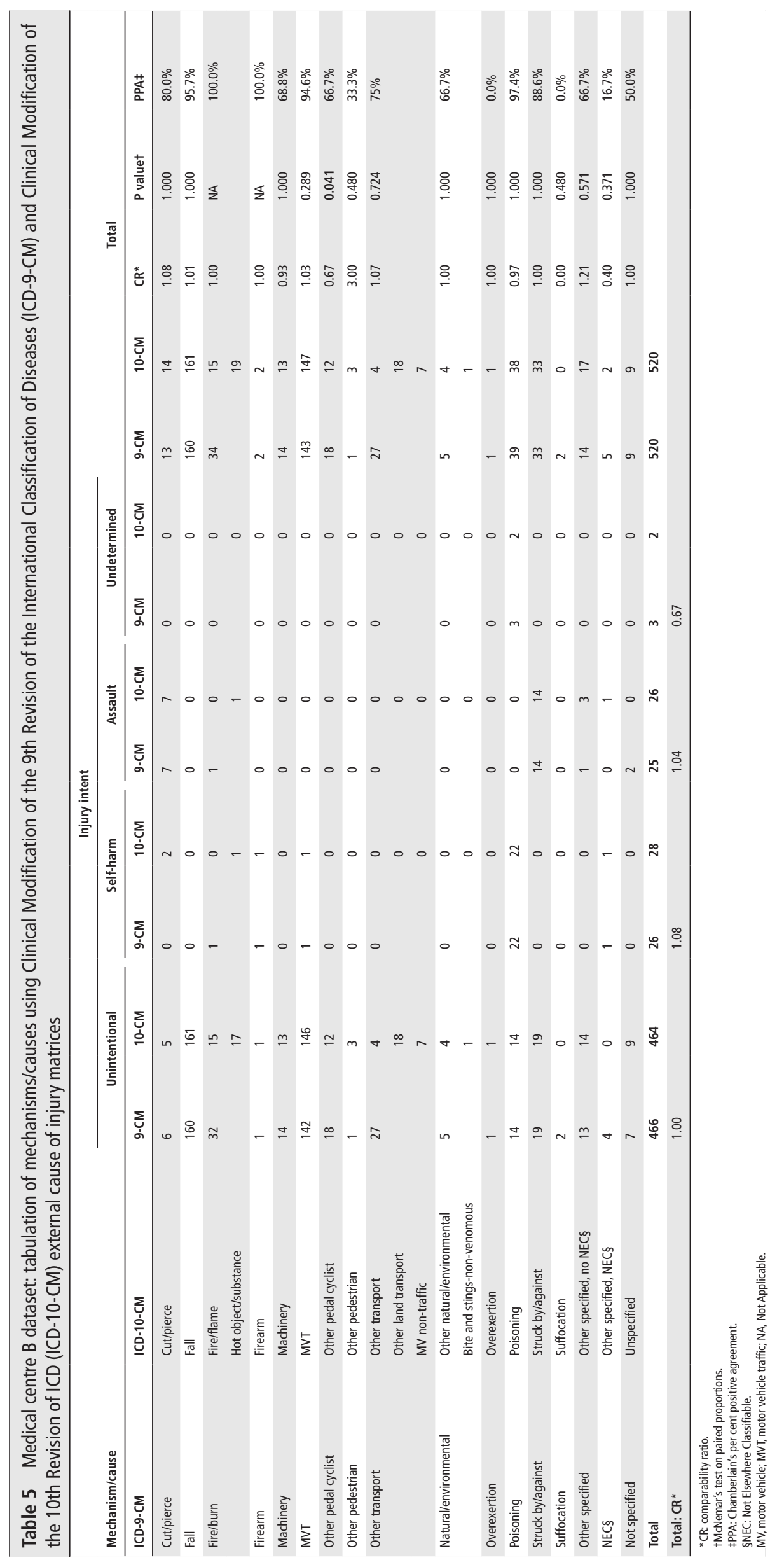




\section{DISCUSSION}

Our study suggests that users of injury morbidity data can anticipate some discontinuities in temporal trends at the injury cause/mechanism level due to the switch from ICD-9-CM to ICD-10-CM on 1 October 2015, and the resulting switch from the ICD-9-CM matrix to the ICD-10-CM matrix. The CRs reported in tables 4 and 5, based on dually coded datasets from two large academic trauma centres, illustrate the potential magnitude of these discontinuities and highlight specific differences between external cause of injury codes in the two code sets. For several mechanisms/causes, the CRs were equal to unity, but different records were classified in the same category (PPA $<100 \%$ ) by the ICD-9-CM and ICD-10-CM matrices.

According to a report of the Injury Surveillance Workgroup, a group of experts assembled by the Safe States Alliance to provide recommendations for injury surveillance and data analysis around the ICD-9-CM to ICD-10-CM transition, changes in the injury counts by category can be explained by changes to coding guidelines, differences in the basic structure of the ICD-9-CM and ICD-10-CM matrices, differences in assignment of external cause codes to specific matrix cells, new or more detailed codes in ICD-10-CM, and other considerations. ${ }^{11}$ We found evidence supporting most of these explanations.

The most common reason for different classification of the same record by the ICD-9-CM and ICD-10-CM matrices was assigning an external cause to different mechanisms/causes. For example, 'MV non-traffic' is a new ICD-10-CM category that was created to support better surveillance of these injuries. As a result, some records assigned to the 'other transport' by the ICD-9-CM matrix (eg, E820-E825, fifth digits 0-4) were reassigned to the new 'MV non-traffic' category by the ICD-10-CM matrix. However, our finding that most of the MCA records reassigned to the new 'MV non-traffic' category were classified as MVT by the ICD-9-CM matrix suggests that some coders became more attentive to the distinction between traffic and non-traffic injuries while they were preparing for ICD-10-CM. 'Other land transport' is another new ICD-10-CM mechanism/ cause that was separated out of the 'other transport' in the ICD-9-CM matrix; however, we observed no cases of differential classification involving this category.

A total of nine discrepancies (three in MCA, six in MCB) involved the ICD-10-CM external cause code of V.19.9 ("pedal cyclist... injured in unspecified traffic accident cause"), which was assigned to the 'MVT pedal cyclist' category by the ICD-10-CM matrix, while the equivalent ICD-9-CM code (E826.1) was assigned to the 'other pedal cyclist' category by the ICD-9-CM matrix. ${ }^{12}$ This choice may reflect an assumption by the developers of the ICD-10-CM matrix that unspecified pedal cyclist traffic injuries are likely to involve an MV.

Sixteen MCA records and three MCB records were classified as fall injuries by the ICD-9-CM matrix, but as overexertion, 'struck by/against', or machinery-related injuries by the ICD-10-CM matrix. One contributing factor is that ICD-10-CM has a specific set of external cause codes for 'slipping, tripping, and stumbling without falling' (W18.4-), which are classified as overexertion injuries by the ICD-10-CM matrix, ${ }^{12}$ whereas the same concept of accidental slipping was indexed to E885.9 ('fall from other slipping, tripping, or stumbling') in ICD-9-CM. The latter code was classified as a fall in the ICD-9-CM matrix, even though it was also used to describe slipping events without falls. Another contributing factor is that ICD-10-CM has codes for 'striking against unspecified object with subsequent fall' (W18.00-) and 'striking against other object with subsequent fall' (W18.09-), whereas ICD-9-CM only offered the options of striking an 'object in sports' (E917.5), 'caused by a crowd, by collective fear or panic' (E917.6), furniture (E917.7), and 'other stationary object' (E917.8), with subsequent fall. A patient who described 'bumping into something and falling' would thus be classified as having had a fall injury by the ICD-9-CM matrix, but as having had a 'struck by/against' injury by the ICD-10-CM matrix. An interrupted time series analysis from Kentucky showed an immediate significant increase in hospitalisation rates for 'struck by/against' injuries in October 2015, presumably also due to this difference between ICD-9-CM and ICD-10-CM. ${ }^{13}$

Finally, 14 discrepancies (10 in MCA, 4 in MCB) involved the 'unspecified' category. The large number of new and more detailed external cause codes in ICD-10-CM allowed some records to be reassigned to other categories by the ICD-10-CM matrix. However, a single ICD-10-CM code (X58, 'exposure to other specified factors') encompasses both the concept of 'other specified (unintentional injury), not elsewhere classifiable' and the concept of unspecified unintentional injury, whereas these concepts were represented by two different codes in ICD-9-CM (E928.8 and E928.9, respectively). As a result, some records categorised as 'other specified' by the ICD-9-CM matrix were categorised as 'unspecified' by the ICD-10-CM matrix. This finding is also consistent with the Kentucky data, which showed an immediate significant increase in 'unspecified' injury hospitalisation rates and a corresponding decrease in 'other specified' injury hospitalisation rates when ICD-10-CM was implemented. ${ }^{13}$

In this study, we conducted parallel analyses of two dually coded datasets without combining them, despite the resulting loss of statistical power. The two participating medical centres used different methods and different time periods for data collection. In addition, state policies and procedures for external cause reporting differed between MCA and MCB. In 20012012, the state where MCA is located had about 6\%-7\% fewer inpatient injury discharges with an external cause code than the state where MCB is located. ${ }^{14} \mathrm{MCA}$ is in a state where five data fields are set aside exclusively for external cause of injury codes, whereas MCB is in a state where external cause codes are mixed with all of the diagnosis codes. These differences may lead coders to code causes of injury with different levels of detail

This study has several limitations. Our data originated from the period before implementation of ICD-10-CM, when coders were being trained and evaluated on their proficiency with ICD-10-CM. As a result, the accuracy of ICD-10-CM code assignment might have been worse than current practice if coders have become more experienced, or better than current practice if coders have become less attentive and less concerned about oversight. At MCA, ICD-9-CM and ICD-10-CM codes were assigned at the same time by the same coder, leading to greater comparability than one might expect in other settings. We classified records based only on the first listed external cause code; considering all external cause codes might have slightly increased agreement. Finally, our data came from only two major academic trauma centres, which were not expected to be representative of the nation, and the number of cases in nearly half of the mechanism/cause categories was too small to draw meaningful conclusions.

\section{CONCLUSION}

Switching to ICD-10-CM and the new version of the External Cause of Injury Matrix may affect injury surveillance statistics. The magnitude of these potential effects can be assessed 
by identifying discontinuities in temporal trends within specific jurisdictions across the ICD-9-CM to ICD-10-CM transition. ${ }^{12}$ Another approach, which has been particularly useful for mortality data, ${ }^{15}$ is to code the same records in both code sets and estimate CRs for specific mechanism/cause categories. With caution and awareness of the study's limitations, injury epidemiologists can use our CRs (where total cell counts are at least 20 ) to estimate the potential impact of ICD-10-CM implementation on observed rates within specific mechanism/cause categories. Future revisions to the ICD-10-CM matrix may change these findings. Analyses of larger and more representative dually coded datasets would help to inform data users around future code set conversions, including the forthcoming conversion to ICD-11.

\section{What is already known on the subject}

- External cause of injury matrices for morbidity data coded using the International Classification of Diseases have proven to be very useful for surveillance and research.

- The new matrix for Clinical Modification of the 10th Revision of International Classification of Diseases (ICD-10-CM) has been extensively tested and refined, but never compared with the Clinical Modification of the 9th Revision of the ICD matrix on the same hospital records.

\section{What this study adds}

- Switching to ICD-10-CM and the new external cause of injury matrix may affect injury surveillance statistics and research, especially for certain mechanisms/causes.

Acknowledgements The authors would like thank Holly Hedegaard, MD, MSPH, Injury Epidemiologist at the National Center for Health Statistics-Division of Analysis and Epidemiology and Renee L. Johnson, RPT, MSPH, Senior Epidemiologist at the National Center for Injury Prevention and Control, CDC - Division of Injury Prevention, Data Analytics Branch for their comments, insightful suggestions, and critical reading of the manuscript.

Contributors Conception and design of study: EP, BS, HB and PSR. Acquisition of data: EP, SHF and PSR. Data analysis and drafting the manuscript: EP. Interpretation of data: EP, SHF, OA and PSR. Revising the manuscript critically: EP, SHF, OA, BS, HB and PSR.

Funding The authors have not declared a specific grant for this research from any funding agency in the public, commercial or not-for-profit sectors.

Disclaimer The contents of this publication are solely the responsibility of the authors and do not necessarily represent the official views of the CDC in the United States Department of Health and Human Services, the State of Colorado, the State of Kentucky, the State of Maryland or the State of Massachusetts.

Competing interests None declared.

Patient consent for publication Not required.

Provenance and peer review Commissioned; externally peer reviewed.

Data availability statement No data are available.

Supplemental material This content has been supplied by the author(s). It has not been vetted by BMJ Publishing Group Limited (BMJ) and may not have been peer-reviewed. Any opinions or recommendations discussed are solely those of the author(s) and are not endorsed by BMJ. BMJ disclaims all liability and responsibility arising from any reliance placed on the content. Where the content includes any translated material, BMJ does not warrant the accuracy and reliability of the translations (including but not limited to local regulations, clinical guidelines, terminology, drug names and drug dosages), and is not responsible for any error and/or omissions arising from translation and adaptation or otherwise.

Open access This is an open access article distributed in accordance with the Creative Commons Attribution Non Commercial (CC BY-NC 4.0) license, which permits others to distribute, remix, adapt, build upon this work non-commercially, and license their derivative works on different terms, provided the original work is properly cited, appropriate credit is given, any changes made indicated, and the use is non-commercial. See: http://creativecommons.org/licenses/by-nc/4.0/.

\section{ORCID iD}

Eduard A Poltavskiy http://orcid.org/0000-0002-4052-8593

\section{REFERENCES}

1 National Center for Health Statistics. International classification of diseases, ninth revision, clinical modification (ICD-9-CM). Available: http://www.cdc.gov/nchs/icd/ icd9cm.htm [Accessed 5 Sept 2016].

2 National Center for Health Statistics. International classification of diseases, tenth revision, clinical modification (ICD-10-CM). Available: http://www.cdc.gov/nchs/icd/ icd10cm.htm [Accessed 5 Sept 2016].

3 Annest J, Hedegaard $H_{\text {, Chen L }}$, et al. Proposed framework for presenting injury data using ICD-10-CM external cause of injury codes, 2014. Available: https://www.cdc. gov/injury/wisqars/pdf/ICD-10-CM_External_Cause_Injury_Codes-a.pdf [Accessed 1 May 2020].

4 World Health Organization. Classification of diseases. Available: http://www.who.int/ classifications/icd/icdonlineversions/en/ [Accessed 5 Sept 2016].

5 National Center for Health Statistics. Tools for categorizing injuries using ICD codes. Available: http://www.cdc.gov/nchs/injury/injury_matrices.htm [Accessed 1 May 2020].

6 Nilson F, Bonander C, Andersson R. The effect of the transition from the ninth to the tenth revision of the International classification of diseases on external cause registration of injury morbidity in Sweden. Inj Prev 2015;21:189-94.

7 Hedegaard HB, Johnson RL, Ballesteros MF. Proposed ICD-10-CM surveillance case definitions for injury hospitalizations and emergency department visits. National health statistics reports, 2017. Available: https://www.cdc.gov/nchs/data/nhsr/ NHSR100.pdf [Accessed 1 May 2020].

8 Hedegaard HB, Johnson RL. An updated international classification of diseases, 10th revision, clinical modification (ICD-10-CM) surveillance case definition for injury hospitalizations. National health statistics reports 2019(125). Available: https://www. cdc.gov/nchs/data/nhsr/nhsr125-508.pdf [Accessed 1 May 2020].

9 Anderson RN, Miniño AM, Hoyert DL, et al. Comparability of cause of death between ICD-9 and ICD-10: preliminary estimates. national vital statistics reports; 49(2). Hyattsville, Maryland: National Center for Health Statistics, 2001. Available: https:// www.cdc.gov/nchs/data/nvsr/nvsr49/nvsr49_02.pdf [Accessed 1 May 2020].

10 Chamberlain J, Rogers P, Price JL, et al. Validity of clinical examination and mammography as screening tests for breast cancer. Lancet 1975;2:1026-30.

11 Injury Surveillance Workgroup Safe States Alliance. The transition from ICD-9-CM to ICD-10-CM: guidance for analysis and reporting of injuries by mechanism and intent (ISW9), 2016. Available: https://cdn.ymaws.com/www.safestates.org/resource/resmgr/ isw9/ISW9_FINAL_Report.pdf [Accessed 1 May 2020].

12 Hedegaard HB, Johnson RL, Garnett MF, et al. The international classification of diseases, 10th revision, clinical modification (ICD-10-CM) external cause-of-injury framework for categorizing mechanism and intent of injury. National health statistics reports 2019(136). Available: https://www.cdc.gov/nchs/data/nhsr/nhsr136-508.pdf [Accessed 1 May 2020].

13 Slavova S, Costich JF, Luu H, et al. Interrupted time series design to evaluate the effect of the ICD-9-CM to ICD-10-CM coding transition on injury hospitalization trends. Inj Epidemiol 2018:5:36.

14 Barrett M, Steiner C, Sheng M, et al. Healthcare cost and utilization project (HCUP) external cause of injury code (E Code) evaluation report (updated with 2013 HCUP data). HCUP methods series report \#2016-03. July 26, 2016. US Agency for Healthcare Research and Quality. Available: http://www.hcup-us.ahrq.gov/reports/ methods/methods.jsp [Accessed 1 May 2020].

15 National Center for Health Statistics. National vital statistics system: comparability of Cause-of-death between ICD revisions. Available: https://www.cdc.gov/nchs/nvss/ mortality/comparability_icd.htm [Accessed 1 May 2020]. 